\title{
Reliability and Validity of the Pediatric Quality of Life Inventory With Individuals With Intellectual and Developmental Disabilities
}

\author{
Michelle A. Viecili and Jonathan A. Weiss
}

\begin{abstract}
The Pediatric Quality of Life Inventory (PedsQL) measures health-related quality of life, a growing area of research, particularly among individuals with disabilities. This research is necessary to fully understand the varied needs of the population and, ultimately, ensure that those needs are being met. The current study assessed the reliability and validity of the PedsQL in individuals with intellectual and developmental disabilities, including individuals with autism spectrum disorder. Participants included 359 caregivers of children, youth, and young adults with IDD. Caregivers completed the PedsQL 4.0 Generic Core Scales questions regarding the individual's physical health and the Strengths and Difficulties Questionnaire. The PedsQL achieved excellent reliability across scales, and distinguished healthy individuals from those with chronic health conditions, as well as individuals with ASD from those without. Factor analysis confirmed a 5-factor model, with moderate to high criterion validity. The PedsQL shows sound psychometric properties and may be a useful tool to measure psychosocial functioning in this population.
\end{abstract}

Key Words: autism spectrum disorder; intellectual disability; health-related quality of life; developmental disability

\section{Introduction}

Research pertaining to the measurement of health-related quality of life (HRQOL), defined as the physical, mental, and social dimensions of quality of life (World Health Organization, 1948), has increased in recent years. Studying HRQOL among individuals with intellectual/developmental disabilities (IDD) is particularly important, given the multifaceted needs of the population and the considerable health-related research in the area. According to the National Coalition on Dual Diagnosis, IDD refers to individuals

...who have significantly greater difficulty than most people with intellectual and adaptive functioning and have had such difficulties from a very early age ... and includes children, youth, and adults with developmental disorders such as Fetal Alcohol Spectrum Disorder and Autism Spectrum Disorders. (2009, p. 2)

It is particularly relevant to examine HRQOL among individuals with IDD as they include conditions that are considered lifelong; are pervasive across contexts; and have significant influence on adaptive functioning, social development, and academic functioning. Individuals with autism spectrum disorder (ASD), intellectual disability (ID), and those with ASD and ID (given that these are not mutually exclusive conditions) consistently experience more emotional and behavioral disorders than peers without these conditions (Totsika, Hastings, Emerson, Berridge, \& Lancaster, 2011), as well as higher physical morbidity (Beange, McElduff, \& Baker, 1995; 
Coury, 2010; van Schrojenstein LantmanDe Valk, Metsemakers, Haveman, \& Crebolder, 2000). Research has shown that quality of life (including HRQOL) is lower in children with IDD compared to those without (Kuhlthau et al., 2010; Limbers, Heffer, \& Varni, 2009; Shipman, Sheldrick, \& Perrin, 2011; Thurston, Paul, Loney, Wong, \& Browne, 2010), making this a critical area of further inquiry. According to a panel of experts on IDD and quality of life, "measuring quality of life infers that we value quality within people's lives and that we want to maintain and enhance the things that already, or could, add worth to people's lives" (Schalock et al., 2002, p. 461). These experts recommend measurement in a broad range of life domains and posit that the main domains are the same for people with and without disabilities. The factors that comprise quality of life are often intervention targets in the IDD field, including physical health (Evenhuis, Henderson, Beange, Lennox, \& Chicoine, 2000), emotional well-being (Taylor, William, \& Willner, 2008), social competence, and inclusion (Carter \& Hughes, 2005), making multidimensional instruments of key importance.

Importance has been placed on developing reliable and valid HRQOL tools to be used as outcome indicators of health-related research (e.g., clinical trials) and as a pediatric population health measure (Canadian Academy of Health Sciences, 2009; Matza, Swensen, Flood, Secnik, \& Leidy, 2004; Varni, Burwinkle, Seid, \& Skarr, 2003). The Pediatric Quality of Life Inventory (PedsQL) is an increasingly used instrument designed to measure multidimensional HRQOL among youth ages 2-18 years and adults (Varni, Burwinkle, \& Seid, 2005; Varni \& Limbers, 2009; Varni, Seid, \& Kurtin, 2001). Self-report and proxy-report forms show high reliability $(\alpha=0.88-0.90)$ and construct validity in a number of populations by distinguishing between healthy individuals and patients with health conditions (Varni et al., 2003; Varni et al., 2001). Research has also demonstrated the usefulness of the PedsQL among pediatric populations with psychiatric disorders, such as in children with attention deficit hyperactivity disorder, anxiety disorder, and disruptive behavior disorders (Bastiaansen, Koot, Bongers, Varni, \& Verhulst, 2004; Bastiaansen, Koot, Ferdinand, \& Verhulst, 2004).

More recently, a number of studies have used the PedsQL with children with ASD. The measure is reported to have excellent reliability and validity, in terms of proxy and self-report (Limbers et al., 2009; Shipman et al., 2011). Researchers have found that children with ASD have lower physical health, psychosocial health, and total summary scores on the PedsQL than typically developing children (Kose et al., 2013). Kose and colleagues (2013) also found that children with autism had lower psychosocial, social, school functioning, and total scores than those with Asperger syndrome and pervasive developmental disorder not otherwise specified (PDD-NOS) and that scores on the PedsQL were negatively correlated with the Childhood Autism Rating Scale, indicating a relationship between ASD symptoms and HRQOL. Kuhlthau and colleagues (2010) examined scores on the PedsQL in a sample of children with chronic conditions and ASD. They found that children with ASD scored lower HRQOL for the total score, psychosocial, emotional, and social functioning than those with chronic conditions, but did not score lower in the areas of physical and school functioning. Shipman and colleagues (2011) utilized adolescent selfreport, in contrast to the previously mentioned studies that utilized proxy report, and found that adolescents with ASD reported lower HRQOL on the PedsQL when compared to population norms across all domains. In line with these studies, it is hypothesized that the sample of children without ASD would have higher PedsQL scores than the ASD sample, on all of the generic core scales, except physical functioning and school functioning. To date though, no studies have used the PedsQL with individuals with ID without ASD, or have examined the psychometric properties of the PedsQL in individuals with ID and ASD.

The present study aims to investigate the feasibility, reliability, and validity of the PedsQL 4.0 Generic Core scales parent-proxy report in a diverse sample of Canadian children, adolescents, and young adults with IDD and, more specifically, those with ID and those with ASD and ID. We hypothesized that the PedsQL would distinguish between children with ASD versus those without, and between youth with an IDD and a chronic health condition from those without. Hypotheses are described in greater detail in the "Statistical Analyses" section below. 


\section{Methods}

\section{Participants}

Participants included 359 caregivers of youth and young adults with IDD, ranging in age from 11-22 years $(M=16.96, S D=3.04)$, with $63.5 \%$ $(n=228)$ being male. Caregivers consisted of mothers $(n=294,82 \%)$, fathers $(n=43,12 \%)$, step-parents $(n=2, .6 \%)$, grandparents $(n=5$, $1.4 \%)$, aunts/uncles $(n=2, .6 \%)$, legal guardians $(n=3, .8 \%)$, and paid caregivers (support workers; $n=2, .6 \%)$. Caregivers were on average 49.2 years old ( $S D=6.01$ years, range $34-74$ years) and $86 \%$ $(n=310)$ female. All youth had at least one IDD diagnosis (i.e., a confirmed cause of ID, such as Down syndrome, or a diagnosis of ASD) and were registered with a community organization that services individuals with ID (e.g., Special Olympics). The majority of youth had previously received an intellectual assessment as part of the diagnostic process $(88 \%, n=317)$, and $57 \%(n=$ 204) were reported to have mild to moderate levels of ID, $18.5 \%(n=67)$ severe to profound levels of ID, and $14.5 \%(n=51)$ indicated that the level of ID was unknown. The most frequently reported diagnoses (not mutually exclusive categories) were of ID (81\%), ASD (34\%), Down syndrome (18\%), fetal alcohol spectrum disorder $(6 \%)$, and cerebral palsy (6\%). A large percentage of the sample was Caucasian (86\%), with smaller percentages indicating Black/African Canadian (1\%), Hispanic (1\%), Asian (5\%), Aboriginal $(2 \%)$, and other $(3 \%)$.

\section{Procedure}

The York University Research Ethics Board approved this study, and all participants provided informed consent before accessing the questionnaire. The current study was part of a larger project examining health and well-being of youth with IDD participating in community-based Special Olympics. All participants were sampled from Special Olympics Ontario (Canada) 20122013 annual registration lists. Special Olympics is a sport organization for youth and adults with IDD, and represents the largest community recreation organization for people with IDD in the world, with approximately 1.4 million registrants each year. Special Olympics is primarily a grassroots community-based organization that provides service to individuals with IDD, similar to the community living movement, and it is possible to sample individuals at such local community-based levels that represent a far greater proportion of individuals with IDD who live in the community than individuals who compete at elite or international levels. In terms of actual involvement in sport activities, $26 \%$ of the sample did not participate or participated only a few times in the last year, while $50 \%$ participated one to four times a month over the last year, and 24\% participated several times per week.

Caregivers of every athlete in Special Olympics Ontario who was between 11 and 21 years of age in 2012-2013 were contacted via email and mail $(N=2,800)$, and invited to participate in an online or paper-and-pencil survey about involvement in Special Olympics. Our sample thus represents 13\% of all contacted athletes in this age range. A comparison with the overall registration dataset revealed that participants did not differ from nonparticipants in athlete age, gender, or geographic distribution (all $p>.05$ ). Participating families were entered into a raffle to win a pizza party for the participant's Special Olympics team. All participants were Canadian and the majority $(98 \%)$ completed their questionnaires on the online Qualtrics data system (www.qualtrics.com).

PedsQL 4.0 (Pediatric Quality of Life Inventory $^{\text {TM }}$ Version 4.0). The 23-item PedsQL 4.0 Generic Core Scales measure four core dimensions of health: a) Physical Functioning (8 items), b) Emotional Functioning (5 items), c) Social Functioning (5 items), and d) School/Work Functioning (5 items). Parent proxy-report includes ages 2 to 4 (toddler), 5 to 7 (young child), 8 to 12 (child), 13 to 18 (adolescent), 18 to 25 (young adult), and over 26 years (adult), and assesses caregivers' perceptions of their youth's HRQOL over the past month compared to sameaged peers. In the current study, the child, adolescent, and young adult versions were used. Items are essentially the same across versions, except for the use of the wording "child," "teen," or "young adult" as the reference group and the use of the wording "Work/Studies" instead of "School" in the young adult group. A 5-point response scale was utilized $(0=$ never a problem; $1=$ almost never a problem; 2 = sometimes a problem; $3=$ often a problem; 4 = almost always a problem).

Items are reverse-scored and linearly transformed to a $0-100$ scale $(0=100,1=75,2=50$, $3=25,4=0)$, so that higher scores indicate better HRQOL. Scale scores are computed by taking a mean of the completed items, which 
accounts for missing data. The Emotional Functioning, Social Functioning, and School Functioning scales are combined to determine a broad Psychosocial Summary score, while a Physical Health Summary score is computed using the Physical Functioning scale. Scale scores are not computed for individuals where more than 50\% of items in the scale are missing (Fairclough \& Cella, 1996). In the current study, one participant was not included in the Physical Functioning scale, two participants were not included in the Social Functioning scale and Psychosocial Summary score, and three participants were not included in the School Functioning scale as a result of missing data.

Strengths and Difficulties Questionnaire. The Strengths and Difficulties Questionnaire (SDQ) is a brief, 25-item behavioral screening questionnaire (Goodman, 1997). The SDQ is completed by caregivers regarding the behavior of their children, typically between the ages of 3-17 years. Given the developmental delays inherent in ID, we used this scale for all participants in the study. Items are grouped into five subscales: Emotional Symptoms (5 items), Conduct Problems (5 items), Hyperactivity/Inattention (5 items), Peer Relationship Problems (5 items), and Prosocial Behavior (5 items). A Total Difficulties score (20 items, not including Prosocial Behavior) can also be computed. Response options include $0=$ not true, 1 = somewhat true, and $2=$ certainly true. A United Kingdom population-based study of the SDQ indicated satisfactory reliability (Cronbach $\alpha=.73$ ) and acceptable sensitivity/specificity, with scores above the $90^{\text {th }}$ percentile predicting a high probability of independently diagnosed psychiatric disorders (mean odds ratio: 15.7 for parent scales; Goodman, 2001). Validity has also been reported when used with individuals with ID and ASD (Emerson, 2005; Kaptein, Jansen, Vogels, \& Reijneveld, 2008).

Demographics and health conditions. Participants completed questions regarding a variety of child and family demographics. To assess for intellectual ability level, participants were asked whether youth had ever received a psychological assessment of intellectual functioning and, if so, to indicate the reported intellectual level. They were also asked to indicate any diagnoses provided by psychologists or medical doctors. To assess for chronic health conditions, participants were asked "Does your child have one or more recurring health conditions that require regular, ongoing care (like epilepsy, heart conditions, asthma, etc.)?" and then asked to indicate the condition (Roman, Knight, Chalfin, \& Popkin, 2009). Reported conditions were then reviewed to ensure that they were indeed chronic. Of the 123 caregivers that indicated the presence of a chronic health condition, the most commonly occurring ones included heart conditions $(n=23)$, epilepsy or reoccurring seizures $(n=24)$, and asthma $(n=21)$.

\section{Statistical Analyses}

Statistical analyses were conducted using SPSS version 18.0. Reliability of the PedsQL Generic Core Scales was assessed using Cronbach's coefficient alpha. The feasibility of the PedsQL as a measure for use in assessing HRQOL in youth with IDD was determined from the percentage of missing values for each item and the distribution of item responses (Essink-Bot, Krabbe, Bonsel, \& Aaronson, 1997; McHorney, Ware, Lu, \& Sherbourne, 1994). Range of measurement was assessed by identifying the percentage of scores at the extremes of the scaling range (ceiling and floor effects; McHorney et al., 1994). It was hypothesized that the PedsQL would demonstrate good feasibility and range of measurement.

Discriminative validity of the PedsQL Generic Core Scales was assessed by comparing youth with a diagnosis of ASD to youth with IDD without ASD. Previous research has found that children with ASD (with or without ID) have greater emotional, behavioral, social, and mental health difficulties than children with ID alone (Bradley, Summers, Wood, \& Bryson, 2004; Smith \& Matson, 2010; Totsika et al., 2011). We hypothesized that the sample of individuals without ASD would have higher PedsQL scores than the ASD sample, on all of the Generic Core Scales, except Physical Functioning and School Functioning, as we were not aware of research indicating poorer overall physical health in children with ASD compared to other IDD, and research has reported lower HRQOL in individuals with ASD compared to those with chronic health conditions on the psychosocial, emotional, and social functioning subscales, and no difference in school or physical health. Construct validity was also assessed by comparing group differences between individuals with and without chronic health issues, using independent samples $t$-tests. Based on previous PedsQL findings (Varni, Burwinkle, Katz, Meeske, 
\& Dickinson, 2002; Varni, Burwinkle, Rapoff, Kamps, \& Olson, 2004; Varni, Seid, et al., 2002), it was anticipated that healthy youth with IDD would have higher PedsQL scores on all subscales compared to children with IDD and chronic health conditions. Effect sizes were calculated to determine the magnitude of the differences, designated as small (0.20), medium (0.50), and large (0.80; Cohen, 1988).

Exploratory factor analysis was utilized to examine the structure of relationships between the items of the PedsQL. As in previous research (Varni et al., 2001) we expected to find a 5-factor structure. To extract the factors, we applied principal component analysis, with oblique rotation (direct oblimin) on the 23 items. Factors with an eigenvalue less than 1 were disregarded.

Convergent validity was assessed through correlations between the Generic Core Scales and scores on the SDQ. It was hypothesized that subscales of the Strengths and Difficulties Questionnaire (Goodman, 1997) would be correlated with subscales of the PedsQL, as both the SDQ and PedsQL measure psychosocial well-being in a variety of domains. It was hypothesized that the Emotional Functioning Scale and Social Functioning Scales (PedsQL) would be negatively correlated with the Emotional Symptom Scale and Peer Problems Scales on the SCQ, respectively, and that the Psychosocial subscale of the PedsQL would be negatively correlated with all scales of the SDQ. The PedsQL Social Functioning Scale was also hypothesized to be positively correlated to the SDQ Prosocial Behavior Scale.

\section{Results}

\section{Reliability}

Internal consistency reliability alpha coefficients for all subscales and the total scores fell within acceptable ranges, with the total score demonstrating excellent internal consistency $(\alpha=.90)$, and subscales demonstrating good internal consistency $(\alpha=.78-89)$. When examining the entire sample of males and females separately, good to excellent internal consistency was found across all subscales and total score for males $(\alpha=76-.90)$ and females $(\alpha=.81-.90)$. When examining those with ASD to those without ASD, again, good to excellent internal consistency values were found (non-ASD group, $\alpha=.77-.90$; ASD group, $\alpha=.78-.91$ ).

\section{Feasibility}

The percentage of missing values was found to be less than 1\%. A full range of measurement was demonstrated for each scale. No floor effects were found within the sample and ceiling effects were minimal (0.3-17.4\%; Table 1) and within acceptable ceiling limits (Terwee et al., 2007).

\section{Discriminative Validity}

Individuals without ASD $(n=233)$ were compared to those with ASD $(n=122)$. Individuals without ASD were more likely to have a chronic health condition, compared to those with ASD, $\chi^{2}(1)=6.71, p=.01$. Thirty-nine percent of the sample of children with ASD was reported to have a chronic health condition, compared to $25 \%$ of children without an ASD. Gender was also significantly different between groups, with those with ASD more likely to be male, $\chi^{2}(1)=11.19$, $p<.001$ (75\% and 57\%, respectively). This gender difference is expected, as ratios of male to females in the ASD population range from 4:1 to $11: 1$ (Chakrabarti \& Fombonne, 2001; Fombonne, 2005; Gillberg, Cederlund, Lamberg, \& Zeijlon, 2006). Groups did not significantly differ on youth age $(t[355]=1.76, p=.08$; see Table 2$)$. Groups significantly differed on the total score and all PedsQL scales, except Physical Functioning, with small to medium effects, with the nonASD group having significantly higher HRQOL than the ASD group.

\section{Construct Validity}

Individuals with IDD with chronic health conditions $(n=123)$ were compared to those without $(n=234)$, using independent samples $t$-tests. As shown in Table 3, the healthy group had significantly higher Total HRQOL, Physical Functioning, and School/Work Functioning than the chronic health condition group, with small to medium effects. Groups did not differ with regard to Emotional Functioning or Social Functioning. Having a health condition was not related to gender $\left(\chi^{2}[1]=1.45, p=.23\right)$ or age $(t[355]=$ $-.25, p=.80)$.

A principal component analysis was conducted on the 23 items with oblique rotation. The Kaiser-Meyer-Olkin (KMO) measure verified the sampling adequacy for the analysis, $\mathrm{KMO}=.87$, and all KMO values for individual items were $>.82$, which is well above the acceptable limit of .5 (Field, 2009). Bartlett's test of sphericity, 
Table 1

Scale Descriptives and Internal Consistency Reliability for PedsQL ${ }^{T M} 4.0$ Proxy-Report

\begin{tabular}{|c|c|c|c|c|c|c|c|}
\hline \multirow[b]{2}{*}{ Functioning Scale } & \multicolumn{6}{|c|}{ Scale Descriptives } & \multirow{2}{*}{$\begin{array}{c}\begin{array}{c}\text { Internal } \\
\text { Consistency }\end{array} \\
\text { Total } \\
\text { Sample }\end{array}$} \\
\hline & $\begin{array}{l}\text { Number of } \\
\text { Items }\end{array}$ & $N$ & Mean & $S D$ & $\begin{array}{l}\text { Percentage } \\
\text { Floor }\end{array}$ & $\begin{array}{l}\text { Percentage } \\
\text { Ceiling }\end{array}$ & \\
\hline Total Score & 23 & 357 & 66.3 & 16.1 & 0.0 & 0.3 & .90 \\
\hline Physical & 8 & 356 & 74.4 & 22.7 & 0.0 & 17.4 & .89 \\
\hline Psychosocial Health & 15 & 355 & 61.8 & 17.2 & 0.0 & 0.3 & .89 \\
\hline Emotional & 5 & 357 & 66.3 & 20.5 & 0.3 & 7.8 & .83 \\
\hline School/Work & 5 & 354 & 62.2 & 18.4 & 0.3 & 3.1 & .78 \\
\hline Social & 5 & 355 & 57.0 & 23.4 & 0.9 & 6.8 & .83 \\
\hline
\end{tabular}

$\mathrm{x}^{2}(136)=2049.83, p<.001$, indicated that correlations between items were sufficiently large for principal component analysis. An eigenvalue cutoff of 1.0 (Kaiser's criterion) resulted in a 5-factor solution that, in combination, explained $60.1 \%$ of the variance. Table 4 shows factor loadings after rotation. Both School Functioning and Social Functioning items split into two different factors, but, otherwise, the factors that emerged are largely consistent with the a priori hypothesized factor structure.

As in the Varni and colleagues (2001) validation study, the school functioning items split into two different factors, with the items relating to missing school loading on a separate factor. In the current study, the social functioning items also split and loaded on these two different factors. The Social Functioning items split into items related to getting along with peers and items related to being able to keep up with/do similar things as peers. The items related to the Emotional and Physical
Functioning scales were consistent with the original PedsQL version (Varni et al., 2001).

\section{Convergent Validity}

We hypothesized that the Emotional Functioning and Social Functioning scales (PedsQL) would be correlated with the Emotional Symptom Score and Peer Problems scale on the SDQ, respectively. It was also hypothesized that the Psychosocial Scale of the PedsQL would be correlated with all subscales of the SDQ. Data from the SDQ were non-normally distributed, with all subscales being positively or negatively skewed. As the SDQ subscales also violated the Shapiro-Wilk test of normality, Spearman's Rho was calculated instead of Pearson correlation coefficients. As expected, the SDQ Emotional Symptom scale was negatively correlated with the PedsQL Emotional Functioning scale, $r_{s}=-.70, p<.001$, and the PedsQL Social Functioning scale was negatively correlated with the SDQ Peer Problems scale, $r_{s}=-.57$,

Table 2

Independent Samples T-Test Examining Differences in PedsQL ${ }^{T M}$ Scores in Those With and Without ASD

\begin{tabular}{|c|c|c|c|c|c|c|c|c|c|}
\hline \multirow[b]{2}{*}{ Functioning Scale } & \multicolumn{2}{|c|}{$\begin{array}{l}\text { Non-ASD } \\
\text { Group }\end{array}$} & \multicolumn{2}{|c|}{ ASD Group } & \multirow[b]{2}{*}{$t(d f)$} & \multirow[b]{2}{*}{$p$} & \multicolumn{2}{|c|}{$95 \% \mathrm{CI}$} & \multirow[b]{2}{*}{ Cohen's $d$} \\
\hline & $M$ & $S D$ & $M$ & $S D$ & & & $L L$ & $U L$ & \\
\hline Physical & 76.31 & 23.37 & 75.89 & 21.22 & $-.90(354)$ & .37 & -7.25 & 2.70 & -.10 \\
\hline Psychosocial Health & 64.49 & 16.42 & 56.66 & 17.46 & $4.16(353)$ & $<.001$ & 4.05 & 11.62 & 0.44 \\
\hline Emotional & 69.84 & 18.89 & 59.50 & 21.65 & $4.66(355)$ & $<.001$ & .598 & 14.70 & 0.49 \\
\hline School/Work & 63.56 & 17.91 & 59.51 & 19.22 & $1.96(352)$ & .05 & -.01 & 9.10 & 0.21 \\
\hline Social & 59.94 & 23.06 & 51.12 & 22.99 & $3.41(353)$ & .001 & 3.72 & 13.89 & 0.36 \\
\hline Total Score & 67.68 & 15.63 & 63.64 & 16.60 & $2.27(355)$ & .02 & .53 & .75 & 0.24 \\
\hline
\end{tabular}

Note. ASD = Autism spectrum disorder; $C I=$ confidence interval; $L L=$ lower limit; $U L=$ upper limit. 
Table 3

Independent Samples T-Test Examining Differences in PedsQL ${ }^{T M}$ Scores in Those With a Chronic Health Condition Versus Those Without

\begin{tabular}{|c|c|c|c|c|c|c|c|c|c|}
\hline \multirow[b]{2}{*}{ Functioning Scale } & \multicolumn{2}{|c|}{$\begin{array}{c}\text { Chronic Health } \\
\text { Condition }\end{array}$} & \multicolumn{2}{|c|}{ No Condition } & \multirow[b]{2}{*}{$t(d f)$} & \multirow[b]{2}{*}{$p$} & \multicolumn{2}{|c|}{$95 \% \mathrm{CI}$} & \multirow[b]{2}{*}{ Cohen's $d$} \\
\hline & $M$ & $S D$ & $M$ & $S D$ & & & $L L$ & $U L$ & \\
\hline Physical & 66.13 & 23.50 & 78.70 & 20.98 & $-5.15(354)$ & $<.001$ & -17.38 & -7.77 & -.55 \\
\hline Psychosocial health & 59.69 & 17.36 & 62.96 & 16.70 & $-1.71(353)$ & .09 & -7.04 & .50 & -.18 \\
\hline Emotional & 65.21 & 21.26 & 66.89 & 20.03 & $-.74(355)$ & .46 & -6.16 & 2.80 & -.08 \\
\hline School/Work & 57.88 & 19.26 & 64.39 & 17.64 & $-3.19(352)$ & .002 & -10.54 & -2.50 & -.34 \\
\hline Social & 55.85 & 22.38 & 57.52 & 23.92 & $-.64(353)$ & .53 & -6.82 & 3.49 & -.07 \\
\hline Total Score & 62.18 & 16.53 & 68.47 & 15.40 & $-3.57(355)$ & $<.001$ & -9.75 & -2.83 & -.38 \\
\hline
\end{tabular}

Note. $C I=$ confidence interval; $L L=$ lower limit; $U L=$ upper limit.

$p<.001$, and positively correlated with the SDQ Prosocial scale, $r_{s}=.27, p<.001$. As shown in Table 5, the PedsQL Psychosocial scale was also negatively correlated with all subscales of the SDQ.

\section{Conclusions}

This study confirms prior research regarding the reliability and validity of the PedsQL ${ }^{\mathrm{TM}} 4.0$ Generic Core Scales. The findings of the present study indicate that the PedsQL Generic Core Scales largely maintain their psychometric properties in a sample of children with IDD, including internal consistency, discriminant validity, construct validity and convergent validity. The present study provides evidence for the utility of the PedsQL Total Scale Score as a clinical trial measure, as this score achieved an alpha of 0.90 , which is at the level recommended for individual patient analysis (Nunnally \& Bernstein, 1994). Subscales of the PedsQL also demonstrated adequate to high internal consistency $(\alpha=.78-.89)$. Research has shown the usefulness of the PedsQL for clinical decision making (de Wit et al., 2008; Seid, Sobo, Gelhard, \& Varni, 2004; Seid et al., 2001; Seid, Varni, Segall, \& Kurtin, 2004), and the reliability and validity found within the present study provide evidence for the utility of the total score as a clinical measure within the IDD population and the utility of the subscales and total score for group level research within the population.

The PedsQL Generic Core scales performed as hypothesized when comparing groups of youth with ASD and ID to those with only ID. Greater emotional, behavioral, social and mental health difficulties, and poorer adaptive skills have been found in individuals with ASD and ID compared to peers with only ID (Bradley et al., 2004; Matson, Rivet, Fodstad, Demsey, \& Boisjoli, 2009; Smith \& Matson, 2010; Totsika et al., 2011). Consistent with this literature, the current study found that individuals with ASD had significantly lower HRQOL in almost all areas of HRQOL except for the Physical domain, where groups did not differ. This fits with the dearth of literature on differences in physical health between children with ASD and ID compared to those with only ID.

The PedsQL Generic Core Scales performed as hypothesized when comparing specific groups of individuals with IDD, with healthy children having greater quality of life than those with chronic health conditions on the PedsQL Total Score, Physical Functioning, and School Functioning subscales. Contrary to hypotheses, no differences were found on the Emotional, Psychosocial, and Social Functioning subscales. Children with IDD (both with ASD and ID) are known to already have significantly more emotional and social problems compared to peers without neurodevelopmental conditions, and the null findings may indicate that, for children with IDD, having a chronic health condition does not significantly influence these already-impaired areas of HRQOL more so than the effect of the IDD itself. Following HRQOL over time, through periods of chronic illness, would provide important within-subject data to assess the effect of health on these domains.

Factor analysis also demonstrated results that are in concordance with previous research. The present study found a 5 -factor solution that in combination explained $60.1 \%$ of the variance. As in previous research with typically developing 
Table 4

Summary of Exploratory Factor Analysis Results for the PedsQL ${ }^{T M}$ Pattern Matrix

\begin{tabular}{|c|c|c|c|c|c|}
\hline Scale/Item & Factor 1 & Factor 2 & Factor 3 & Factor 4 & Factor 5 \\
\hline \multicolumn{6}{|l|}{ Emotional Functioning } \\
\hline Feel afraid or scared & .79 & -.00 & -.04 & .03 & .02 \\
\hline Feel sad or blue & .71 & -.01 & .07 & .03 & .11 \\
\hline Feel angry & .61 & .05 & -.01 & .05 & .20 \\
\hline Trouble sleeping & .77 & -.07 & -.04 & -.08 & -.03 \\
\hline Worry about what will happen & .78 & .16 & .10 & .16 & -.07 \\
\hline \multicolumn{6}{|l|}{ Physical functioning } \\
\hline Hard to walk more than one block & -.17 & -.80 & .19 & .00 & -.00 \\
\hline Hard to run & -.10 & -.86 & .09 & -.06 & -.04 \\
\hline Hard to do sports or exercises & -.06 & -.86 & .04 & -.03 & -.05 \\
\hline Hard to lift something heavy & .02 & -.82 & -.08 & -.02 & -.06 \\
\hline Hard to take bath or shower & -.05 & -.75 & -.12 & .13 & -.06 \\
\hline Hard to do chores around house & .15 & -.71 & -.17 & .16 & -.09 \\
\hline Hurt or ache & .20 & -.51 & .17 & .01 & .06 \\
\hline Low energy & .27 & -.59 & .06 & -.01 & .05 \\
\hline \multicolumn{6}{|l|}{ School/Work Functioning } \\
\hline Hard to concentrate & -.04 & -.01 & .03 & .86 & .04 \\
\hline Forget things & -.01 & .00 & -.00 & .83 & -.01 \\
\hline Trouble keeping up with schoolwork & .11 & -.35 & -.45 & .90 & -.03 \\
\hline Miss school—not well & .34 & -.26 & .57 & .02 & .07 \\
\hline Miss school—doctor appointment & .05 & -.28 & .62 & .15 & .20 \\
\hline \multicolumn{6}{|l|}{ Social Functioning } \\
\hline Trouble getting along w/peers & .06 & .02 & .06 & .01 & .80 \\
\hline Other kids not wanting to be friend & -.01 & .06 & -.06 & .01 & .89 \\
\hline Teased & -.02 & .12 & .08 & .06 & .81 \\
\hline Doing things other peers do & .22 & -.32 & -.51 & .10 & .37 \\
\hline $\begin{array}{l}\text { Hard to keep up when play with } \\
\text { others }\end{array}$ & .11 & -.35 & -.45 & .10 & .43 \\
\hline Eigenvalues & 7.46 & 3.57 & 1.57 & 1.37 & 1.03 \\
\hline Percent Variance & 32.45 & 15.53 & 6.8 & 5.97 & 4.46 \\
\hline
\end{tabular}

youth and youth with ASD (Limbers et al., 2009; Varni et al., 2001), the School/Work Functioning scale had two separate factors, highlighting two constructs: school-related cognitive functioning and school absenteeism. An unexpected finding from this analysis was that the two items from the Social domain that involved keeping up with peers (i.e., "Doing things other peers do" and "Hard to keep up when play with others") loaded with items related to school absenteeism ("Missing school due to illness" and "Missing school due to doctors appointment"), while the other items from the Social domain relate to social inclusion. We are not aware of other studies examining the PedsQL that have found this pattern of loadings. It may be that the same issues that affect school attendance also make it difficult maintaining abilities relative to peers. For example, a high level of mental or physical health problems has been known to interfere with school and social competence (Haynes, 2003; Powers, Patton, Hommel, \& Hershey, 2003; Sawyer et al., 2002). Our results highlight the importance of examining the interplay between School/Work Functioning and Social domains. Future research can further examine whether the instrument better assesses the following subdomains of HRQOL: Physical Functioning, Emotional Functioning, Academic/ Work Competence, Social Functioning, and Maintaining School/Social Involvement. 
Table 5

Spearman's Correlations Between PedsQL $L^{T M}$ and SDQ Subscale Scores

\begin{tabular}{|c|c|c|c|c|c|c|c|c|}
\hline Variable & 1. & 2. & 3. & 4. & 5. & 6. & 7. & 8. \\
\hline 1. PedsQL Emotional Functioning & - & & & & & & & \\
\hline 2. PedsQL Psychosocial Functioning & $.84 * *$ & - & & & & & & \\
\hline 3. PedsQL Social Functioning & $.55^{* *}$ & $.84 * *$ & - & & & & & \\
\hline 4. SDQ Emotional Symptoms & $-.70 * *$ & $-.61 * *$ & $-.40 * *$ & - & & & & \\
\hline 5. SDQ Prosocial & $.20 * *$ & $.25^{* *}$ & $.27 * *$ & $-.13^{*}$ & - & & & \\
\hline 6. SDQ Conduct Problems & $-.44 * *$ & $-.47 * *$ & $-.38 * *$ & $.39 * *$ & $-.25^{* *}$ & - & & \\
\hline 7. SDQ Hyperactivity & $-.35^{* *}$ & $-.42 * *$ & $-.30 * *$ & $.35^{* *}$ & $-.32 * *$ & $.39 * *$ & - & \\
\hline 8. SDQ Peer Problems & $-.46^{* *}$ & $-.57 * *$ & $-.57^{* *}$ & $.40 * *$ & $-.41 * *$ & $.33 * *$ & $.34 * *$ & - \\
\hline 9. SDQ Difficulties & $-.68 * *$ & $-.75^{* *}$ & $-.60 * *$ & $.74 * *$ & $-.38 * *$ & $.66^{* *}$ & $.74 * *$ & $.72 * *$ \\
\hline
\end{tabular}

Note. SDQ $=$ Strengths and Difficulties Questionnaire.

*p $p .01, * * p<.001$

Additionally, similar constructs on another measure, the SDQ, were correlated with PedsQL subscales. As expected, the SDQ Emotional Symptom scale was negatively correlated with the PedsQL Emotional Functioning scale, the PedsQL Social Functioning scale was negatively correlated with the SDQ Peer Problems scale and positively correlated with the SDQ Prosocial scale, and the PedsQL Psychosocial scale was negatively correlated with all subscales of the SDQ. These results lend evidence to the utility of the PedsQL as a measure of emotional and social functioning and well-being in individuals with IDD, as the SDQ has previously been shown to be a valid assessment tool for these constructs (Emerson, 2005).

The present study has some limitations. The sample was recruited from Special Olympics Ontario participant lists, and while Special Olympics is a community-based organization that is accessible across the province that caters to a wide range of physical ability levels and youth with mild to severe levels of ID, results may not generalize to youth with ID who do not participate in the sport programming. For example, by virtue of being a sport organization, youth may be healthier than peers who do not participate. At the same time, we did find that, even within this sample, many individuals had chronic health conditions, and that they showed predictably lower health-related quality of life compared to those without health conditions. Although the current results are important, as they utilize a community sample as opposed to a clinical sample, the factor structure may not be the same for a non-Special Olympics sample of individuals with ID. Another limitation is the reliance only on the caregiver version of the scale, as research has demonstrated imperfect agreement between children and parents, as well as between parents and professionals, on quality of life in populations of youth with and without disabilities (Eiser \& Morse, 2001; Upton, Lawfod, \& Eiser, 2008; White-Koning, Grandjean, Colver, \& Arnaud, 2008). Future research should determine the validity and reliability of the PedsQL as a measure from multiple perspectives.

In conclusion, the study results indicate that the PedsQL Total Score and subscales have acceptable internal consistency and the measure has acceptable discriminant, construct, and convergent validity in a sample of youth with IDD. The present study adds to the literature on HRQOL by demonstrating the utility of the PedsQL for use with children, youth, and young adults with IDD and the reliability and validity of their caregiver's report. It is important to develop and evaluate HRQOL tools that can be used for clinical and research purposes to study HRQOL in individuals with IDD across the lifespan, for comparison purposes, population-based studies, needs assessments, and treatment trials (Limbers et al., 2009).

\section{References}

Bastiaansen, D., Koot, H. M., Bongers, I. L., Varni, J. W., \& Verhulst, F. C. (2004). Measuring quality of life in children referred for psychiatric problems: Psychometric properties of the PedsQL 4.0 generic core scales. Quality of Life Research, 13(2), 489-495.

Bastiaansen, D., Koot, H. M., Ferdinand, R. F., \& Verhulst, F. C. (2004). Quality of life in 
children with psychiatric disorders: Self-, parent, and clinician report. Journal of the American Academy of Child and Adolescent Psychiatry, 43(2), 221-230. http://dx.doi.org/ 10.1097/00004583-200402000-00019

Beange, H., McElduff, A., \& Baker, W. (1995). Medical disorders of adults with mental retardation: A population study. American Journal of Mental Retardation, 99(6), 595-604.

Bradley, E. A., Summers, J. A., Wood, H. L., \& Bryson, S. E. (2004). Comparing rates of psychiatric and behavior disorders in adolescents and young adults with severe intellectual disability ith and without autism. Journal of Autism and Developmental Disorders, 34(2), 151-161. http://dx.doi.org/10.1023/B:JADD. 0000022606.97580.19

Canadian Academy of Health Sciences. (2009). Making an impact: A preferred framerwork and indicators to measure returns on investment in health research. Ottawa, Canada: The Academy.

Carter, E. W., \& Hughes, C. (2005). Increasing social interaction among adolescents with intellectual disabilities and their general education peers: Effective interventions. Research \& Practice for Persons with Severe Disabilities, 30(4), 179-193.

Chakrabarti, S., \& Fombonne, E. (2001). Pervasive developmental disorders in pre-school children. JAMA-Journal of the American Medical Association, 285, 3093-3099.

Cohen, J. (1988). Statistical power analysis for the behavioral sciences (2nd ed). Hillsdale, NJ: Erlbaum.

Coury, D. (2010). Medical treatment of autism spectrum disorders. Current Opinion in Neurology, 23(2), 131-136. http://dx.doi.org/10. 1097/WCO.0b013e32833722fa

de Wit, M., de Waal, H. A., Alle Bokma, J., Haasnoot, K., Houdijk, M. C., Gemke, R. J., \& Snoek, F. J. (2008). Monitoring and discussing health related quality of life in adolescents with type 1 diabetes improves psychosocial well-being: A randomized controlled trial. Diabetes Care, 31, 1521-1526. http://dx.doi.org/10.2337/dc08-0394

Eiser, C., \& Morse, R. (2001). Can parents rate their child's health related quality of life? Results from a systematic review. Quality of Life Research, 10, 347-357.

Emerson, E. (2005). Use of the Strengths and Difficulties Questionnaire to assess the mental health needs of children and adolescents with intellectual disabilities. Journal of
Intellectual and Developmental Disability, 30(1), 14-23. http://dx.doi.org/10.1080/13668250 500033169

Essink-Bot, M. L., Krabbe, P. F. M., Bonsel, G. J., \& Aaronson, N. K. (1997). An empirical comparison of four generic health status measures: The Nottingham Health Profile, the Medical Outcomes Study 36-Item ShortForm Health Survey, the COOP/WONCA Charts, and The EuroQol Instrument. Medical Care, 35(5), 522-537. http://dx.doi.org/ 10.1097/00005650-199705000-00008

Evenhuis, H., Henderson, C. M., Beange, H., Lennox, N., \& Chicoine, B. (2000). Healthy ageing: Adults with intellectual disabilities: Physical health issues. Geneva, Switzerland: World Health Organization.

Fairclough, D. L., \& Cella, D. F. (1996). Functional assessment of cancer therapy (FACT-G): Non-response to individual questions. Quality of Life Research, 5, 321-9. http:// dx.doi.org/10.1007/BF00433916

Field, A. (2009). Discovering statistics using SPSS ( ${ }^{\text {rd }}$ ed.). London, Canada: Sage Publications Ltd.

Fombonne, E. (2005). The changing epidemiology of autism. Journal of Applied Research in Intellectual Disabilities, 18(4), 281-294. http:// dx.doi.org/10.1111/j.1468-3148.2005.00266.x

Gillberg, C., Cederlund, M., Lamberg, K., \& Zeijlon, L. (2006). Brief report: "the autism epidemic". The registered prevalence of autism in a Swedish urban area. Journal of Autism and Developmental Disorders, 36(3), 429-435. http://dx.doi.org/10.1007/s10803-006-0081-6

Goodman, R. (1997). The Strengths and Difficulties Questionnaire: A research note. Journal of Child Psychology and Psychiatry, 38(5), 581586. http://dx.doi.org/10.1111/j.1469-7610. 1997.tb01545.x

Goodman, R. (2001). Psychometric properties of the Strengths and Difficulties Questionnaire (SDQ). Journal of the American Academy of Child and Adolescent Psychiatry, 40, 1337-1345.

Haynes, N. M. (2003). Addressing students' social and emotional needs: the role of mental health teams in schools. Journal of Health o Social Policy, 16(1-2), 109-123. http://dx.doi. org/10.1300/J045v16n01_10

Kaptein, S., Jansen, D. E. M. C., Vogels, A. G. C., \& Reijneveld, S. A. (2008). Mental health problems in children with intellectual disability: Use of the Strengths and Difficulties Questionnaire. Journal of Intellectual Disability 
Research, 52, 125-131. http://dx.doi.org/10 1111/j.1365-2788.2007.00978.x

Kose, S., Erermis, S., Ozturk, O., Ozbaran, B., Demiral, N., Bildik, T., \& Aydin, C. (2013). Health related quality of life in children with autism spectrum disorders: The clinical and demographic related factors in Turkey. $R e^{-}$ search in Autism Spectrum Disorders, 7(2), 213-220. http://dx.doi.org/10.1016/j.rasd.2012. 09.009

Kuhlthau, K., Orlich, F., Hall, T. A., Sikora, D., Kovacs, E. A., Delahaye, J., \& Clemons, T. E. (2010). Health-related quality of life in children with autism spectrum disorders: Results from the Autism Treatment Network. Journal of Autism and Developmental Disorders, 40(6), 721-729.

Limbers, C. A., Heffer, R. W., \& Varni, J. W. (2009). Health-related quality of life and cognitive functioning from the perspective of parents of school-aged children with Asperger's syndrome utilizing the PedsQL ${ }^{\mathrm{TM}}$. Journal of Autism and Developmental Disorders, 39(11), 1529-1541. http://dx.doi.org/10.1007/ s10803-009-0777-5

Matson, J. L., Rivet, T. T., Fodstad, J. C., Dempsey, T., \& Boisjoli, J. A. (2009). Examination of adaptive behavior differences in adults with autism spectrum disorders and intellectual disability. Research in Developmental Disabilities, 30(6), 1317-1325.

Matza, L. S., Swensen, A. R., Flood, E. M., Secnik, K., \& Leidy, N. K. (2004). Assessment of health-related quality of life in children: a review of conceptual, methodological, and regulatory issues. Value in Health, 7(1), 79-92. http://dx.doi.org/10.1111/j.1524-4733.2004. 71273.x

McHorney, C. A., Ware, J. E., Lu, J. F. R., \& Sherbourne, C. D. (1994). The MOS 36-item short-form health survey (SF-36): III Tests of data quality, scaling assumptions, and reliability across diverse patient groups. Medical Care, 32, 40-66.

National Coalition on Dual Diagnosis. (2009). Dual diagnosis glossary. Retrieved from http:// care-id.com/images/File/glossary.doc

Nunnally, J. C., \& Bernstein, I. R. (1994). Psychometric theory (3rd ed.), New York, NY: McGraw-Hill.

Powers, S. W., Patton, S. R., Hommel, K. A., \& Hershey, A. D. (2003). Quality of Life in Childhood Migraines: Clinical Impact and
Comparison to Other Chronic Illnesses. Pediatrics, 112(1), e1-e5. http://dx.doi.org/ 10.1542/peds.112.1.e1

Roman, C. G., Knight, C. R., Chalfin, A., \& Popkin, S. J. (2009). The relation of the perceived environment to fear, physical activity, and health in public housing developments: Evidence from Chicago. Journal of Public Health Policy, 30, S286-S308. http://dx. doi.org/10.1057/jphp.2008.62

Sawyer, M. G., Whaites, L., Rey, J. M., Hazell, P. L., Graetz, B. W., \& Baghurst, P. (2002). Health-related quality of life of children and adolescents with mental disorders. Journal of the American Academy of Child \& Adolescent Psychiatry, 41(5), 530-537. http://dx.doi.org/ 10.1097/00004583-200205000-00010

Schalock, R. L., Brown, I., Brown, R., Cummins, R.A., Felce, D., Matikka, L., ... Parmenter, T. (2002). Conceptualization, measurement, and application of quality of life for persons with intellectual disabilities: Report of an international panel of experts. Mental Retardation, 40, 457-470. http://dx.doi.org/10.1352/00476765(2002)040\%3C0457:CMAAOQ\%3E2.0. $\mathrm{CO} ; 2$

Seid, M., Sobo, E. J., Gelhard, L. R., \& Varni, J. W. (2004). Parents' reports of barriers to care for children with special health care needs: Development and validation of the Barriers to Care Questionnaire. Ambulatory Pediatrics, 4, 323-331. http://dx.doi.org/10.1367/A03198R.1

Seid, M., Varni, J. W., Bermudez, L. O., Zivkovic, M., Far, M. D., Nelson, M., \& Kurtin, P. S. (2001). Parents' perceptions of primary care: Measuring parents' experiences of pediatric primary care quality. Pediatrics, 108, 264-270. http://dx.doi.org/10.1542/peds.108. 2.264

Seid, M., Varni, J. W., Segall, D., \& Kurtin, P. S. (2004). Health related quality of life as a predictor of pediatric healthcare costs: A two-year prospective cohort analysis. Health and Quality of Life Outcomes, 2(48), 1-10.

Shipman, D. L., Sheldrick, R. C., \& Perrin, E. C. (2011). Quality of life in adolescents with autism spectrum disorders: Reliability and validity of self-reports. Journal of Developmental \& Behavioral Pediatrics, 32(2), 85-89. http:// dx.doi.org/10.1097/DBP.0b013e318203e558

Smith, K. R., \& Matson, J. L. (2010). Social skills: Differences among adults with intellectual 
disabilities, co-morbid autism spectrum disorders and epilepsy. Research in Developmental Disabilities, 31(6), 1366-1372. http://dx.doi. org/10.1016/j.ridd.2010.07.002

Taylor, J., William, L., \& Willner, P. (2008). CBT for people with intellectual disabilities: emerging evidence, cognitive ability and IQ effects. Behavioural and Cognitive Psychotherapy, 36(6), 723-733. http://dx.doi.org/10.1017/ S1352465808004906

Terwee, C., Bot, S., de Boer, M., van der Windt, D., Knol, D. L., Dekker, J., ... de Vet, H. C. W. (2007). Quality criteria were proposed for measurement properties of health status questionnaires. Journal of Clinical Epidemiology, 60, 34-42. http://dx.doi.org/10.1016/j. jclinepi.2006.03.012

Thurston, S., Paul, L., Loney, P., Wong, M., \& Browne, G. (2010). The quality of life of a multidiagnosis group of special needs children: Associations and costs. International Journal of Pediatrics, 2010, 1-13. http://dx.doi. org/10.1155/2010/940101

Totsika, V., Hastings, R. P., Emerson, E., Berridge, D. M., \& Lancaster, G. A. (2011). Behavior problems at 5 years of age and maternal mental health in autism and intellectual disability. Journal of Abnormal Child Psychology, 39(8), 1137-1147. http://dx.doi.org/10. 1007/s10802-011-9534-2

Upton, P., Lawford, J., \& Eiser, C. (2008). Parentchild agreement across child health-related quality of life instruments: A review of the literature. Quality of Life Research, 17(6), 895-913. http://dx.doi.org/10.1007/s11136008-9350-5

van Schrojenstein Lantman-De Valk, H. M. J., Metsemakers, J. F., Haveman, M. J., \& Crebolder, H. F. J. M. (2000). Health problems in people with intellectual disability in general practice: a comparative study. Family Practice, 17, 405-407. http://dx.doi. org/10.1093/fampra/17.5.405

Varni, J. W., Burwinkle, T. M., Katz, E. R., Meeske, K., \& Dickinson, P. (2002). The PedsQL ${ }^{\mathrm{TM}}$ in pediatric cancer: Reliability and validity of the Pediatric Quality of Life Inventory $^{\mathrm{TM}}$ Generic Core Scales, Multidimensional Fatigue Scale, and Cancer Module. Cancer, 94, 2090-2106.

Varni, J. W., Burwinkle, T. M., Rapoff, M. A., Kamps, J. L., \& Olson, N. (2004). The PedsQL ${ }^{\mathrm{TM}}$ in pediatric asthma: Reliability and validity of the Pediatric Quality of Life Inventory ${ }^{\mathrm{TM}}$ Generic Core Scales and Asthma Module. Journal of Behavioral Medicine, 27, 297-318.

Varni, J. W., Burwinkle, T., \& Seid, M. (2005). The PedsQL ${ }^{\mathrm{TM}}$ as a pediatric patient reported outcome: Reliability and validity of the PedsQL ${ }^{\mathrm{TM}}$ Measurement Model in 25,000 children. Expert Review of Pharmacoeconmics and Outcome Research, 5, 705-719.

Varni, J., Burwinkle, T., Seid, M., \& Skarr, D. (2003). The PedsQL 4.0 as a pediatric population health measure: feasibility, reliability, and validity. Ambulatory Pediatrics, 3(6), 329-41. http://dx.doi.org/10.1367/1539-4409(2003) 003\%3C0329:TPAAPP\%3E2.0.CO;2

Varni, J. W., \& Limbers, C. A. (2009). The pediatric quality of life inventory: measuring pediatric health-related quality of life from the perspective of children and their parents. Pediatric Clinics of North America, 56(4), 843-863. http://dx.doi.org/10.1016/j.pcl.2009.05.016

Varni, J. W., Seid, M., Knight, T. S., Burwinkle, T., Brown, J., \& Szer, I. S. (2002). The PedsQL ${ }^{\mathrm{TM}}$ in pediatric rheumatology: Reliability, validity, and responsiveness of the Pediatric Quality of Life Inventory ${ }^{\mathrm{TM}}$ Generic Core Scales and Rheumatology Module. Arthritis and Rheumatism, 46, 714-725.

Varni, J. W., Seid, M., \& Kurtin, P. S. (2001). PedsQL4.0 ${ }^{\text {TM}}$ : Reliability and validity of the Pediatric Quality of Life Inventory ${ }^{\mathrm{TM}}$ Version 4.0 Generic Core Scales in healthy and patient populations. Medical Care, 39, 800-812.

White-Koning, M., Grandjean, H., Colver, A., \& Arnaud, C. (2008). Parent and professional reports of the quality of life of children with cerebral palsy and associated intellectual impairment. Developmental Medicine \& Child Neurology, 50(8), 618-624. http://dx.doi.org/ 10.1111/j.1469-8749.2008.03026.x

World Health Organization. (1948). Constitution of the World Health Organization basic document. Retrieved from http://www.who.int/ library/collections/historical/en/index3.html

Received 12/13/2013, accepted 7/16/2014.

The authors would like to thank Dr. Jennine Rawana for her review of this manuscript. This research is supported by the Department of Canadian Heritage 
(Sport Canada) and the Social Sciences and Humanities Research Council. Dr. Weiss is supported by a Chair in Autism Spectrum Disorders Treatment and Care Research (Canadian Institutes of Health Research).

This research is supported by an Insight Grant from the Social Sciences and Humanities Research Council and Department of Canadian Heritage (Sport Canada) and by the Chair in Autism Spectrum Disorders Treatment and Care Research (\#RN284208; Canadian Institutes of Health Research in partnership with NeuroDevNet, Sinneave Family Foundation, CASDA, Autism Speaks Canada, and Health Canada). The authors wish to thank Dr. Jennine Rawana for her review of this manuscript, Special Olympics Ontario, and the many families who participated in this research.

\section{Authors:}

Michelle A. Viecili and Jonathan A. Weiss, York University.

Correspondence concerning this article should be addressed to Jonathan A. Weiss, York University Department of Psychology, 4700 Keele Street, Toronto, ON, M3J1P3, Canada (e-mail: jonweiss@yorku.ca). 